Tab. 2

Cd(II)-Werte im Serum und Uri Serum- und Urin-Werte stammen nicht vom gleichen Probanden

\begin{tabular}{cccc}
\hline Nr. & $\begin{array}{c}\text { Serum } \\
{[\mu \mathrm{g} 100 \mathrm{~m} l \mathrm{Cd}(\mathrm{II})]}\end{array}$ & $\begin{array}{c}\text { Urin } \\
{[\mu \mathrm{g} \mathrm{Cd}(\mathrm{II}) / \mathrm{Tag}]}\end{array}$ & $\begin{array}{c}\text { Urinmenge } \\
{[\mathrm{m} l]}\end{array}$ \\
\hline 1 & 0,24 & 0,73 & 2200 \\
2 & 0,32 & 1,26 & 870 \\
3 & 0,16 & 1,34 & 1200 \\
4 & 0,47 & 1,57 & 1800 \\
5 & 0,16 & 0,34 & 800 \\
6 & 0,22 & 0,58 & 730 \\
7 & 0,23 & 0,77 & 1200 \\
8 & 0,25 & 0,54 & 850 \\
9 & 0,40 & 1,07 & 1920 \\
10 & 0,92 & 1,02 & 1455 \\
11 & 0,12 & 1,25 & 1120 \\
12 & 0,90 & 0,57 & 1250 \\
13 & 0,18 & 0,99 & 1270 \\
14 & 0,22 & 1,33 & 940 \\
15 & 0,18 & 1,31 &
\end{tabular}

Wir konnten somit die von Burt (6) gemessenen hohen $\mathrm{Cd}(\mathrm{II})$-Werte im Serum $(40 \mu \mathrm{g} / 100 \mathrm{~m} /)$ nicht bestätigen. Die Angaben von KLaus (7) $(4 \mu \mathrm{g} / 100 \mathrm{~m} /)$ und Pulido und Mitarbeiter (3) $(1 \mu \mathrm{g} / 100 \mathrm{ml})$ beziehen sich nur auf Einzelproben.

Die Werte unserer Harnanalysen stimmen etwa mit denen spektrographisch von IMBUS (8) ermittelten überein $(1,15 \mu \mathrm{g} / D)$; sie liegen aber wesentlich unter denen von Pulido (3), Klaus (7), Smith (9) sowie Perry und Perry (10). Angesichts der stark wechselnden Harntagesmengen erscheinen uns die Angaben als Konzentrationen unzweckmäßig. Wir beziehen deshalb die Cd(II)-Ausscheidung auf den 24-Stdn.-Urin.

\title{
Literatur
}

1. Tipton, J. H., in: Metall-Binding in Medicine, S. 27, hrsg. von M. J. Seven, J. B. Lippincott Co., Philadelphia (1960). - 2. Schroeder, H. A., J. chron. Dis. 18, 647 (1965). - 3. Pulido, P., K. Fuwa und B. L. VAlleE, Analyt. Biochem. (New York) 14, 393 (1966). - 4. Lehnert, G., und K. H. Schaller, Med. Welt 18, 1131 (1967). - 5. WiLlis, J. B., Analytic. Chem. 34, 614 (1962).
- 6. Burt, E. M., Arch. Environ. Health 8, 60 (1964). - 7 . Klaus, R., diese Z. 4, 299 (1966). - 8. Imbus, H. R., Arch. Environ. Health 6, 112 (1963). - 9. Smrth, J. C. und J. E. KeNCH, Brit. J. industr. Med. 14, 240 (1957). - 10. PerRY, H. M. jr. und E. F. PerRy, J. Clin. Invest. 38, 1452 (1959).

Dr. med: G. Lehnert

852 Erlangen, Schillerstr. 25

\section{Photometrische Mikromethode für die komplexometrische Titration von Calcium}

\author{
Von R. Quicker und H.-J. Dulce \\ Aus dem Institut für Angewandte Pbysiologische Chemie und Klinische Chemie der Freien Universität Berlin
}

(Direktor: Prof. Dr. H.-J. Dulce)

(Eingegangen am 19. Mai 1967)

Es wird eine automatische Calciumtitration mit Äthylendiamintetraessigsäure (EDTA) und Ammoniumpurpurat als Indikator in stark alkalischem Medium für einen Bereich von 2-15 $\mu \mathrm{g}$ Calcium pro Ansatz angegeben. Der maximale Fehler der Einzelbestimmung beträgt $0,13 \mu \mathrm{g}$, der mittlere Fehler im Bereich von 6-15 $\mu \mathrm{g}$ Calcium pro Ansatz etwa 1,5\%.

A method is reported for the automatic titration of calcium with ethylenediaminetetraacetic acid (EDTA) and ammonium purpurate as indicator in strongly alkaline medium. The concentration range is 2-15 $\mu \mathrm{g}$ calcium per sample. The maximum error of a single determination is $0.13 \mu \mathrm{g}$; the average error in the range $6-15 \mu \mathrm{g}$ calcium per sample is about $1.5 \%$.

Die manganometrische Bestimmung des Calciums nach Fällung als Oxalat (1) war früher die Standardmethode für die Untersuchungen in biologischen Flüssigkeiten, erforderte aber größere Serummengen und sorgfältiges Arbeiten. Sie wurde abgelöst durch die komplexometrische Methode nach SchwarzenBach (2) und Ellrotr (3). Die Schwierigkeit dieser Methode ist die exakte Endpunktbestimmung.

Fales (4), Kibrick (5) und Siegmund und Dulce (6) erarbeiteten deshalb eine Mikromethode für die komplexometrische Bestimmung mit $0,1 \mathrm{~m} l$ Untersuchungslösung und photometrischer Endpunktanzeige. Für Serienbestimmungen ist sie geeignet. Es müssen aber die Titrationen von Hand erfolgen und zur Ermittlung der Äquivalenzpunkte Titrationskurven gezeichnet werden. Wir haben jetzt für diese Mikromethode die Titration und Meßwertregistrierung automatisiert. Weiterhin wurde die Methode durch Stabilisierung des Indikators und Anwendung magnetischer Rührung verbessert. COpp (7) hat kürzlich eine ähnliche Mikromethode.für
Calciumbestimmungen angegeben, bei der das Mischen mit einem normalen Rührer vorgenommen wurde. Dies hat den Nachteil, daß die Oberfläche der Lösung nicht ruhig bleibt, die Photometeranzeige schwankt und die automatische Registrierung ungenau wird.

\section{Methodik}

Prinzip

Calciummurexid (rot) besitzt im stark alkalischen Medium $\mathrm{pH}>12$ eine vom freien Murexid (blauviolett) unterschiedliche Farbe. Der Aquivalenzpunkt der Titration ist visuell schlecht, photometrisch gut bestimmbar $(8,9,10)$.

Die Absorptionsspektren von Murexid und seinem Calciumchelat (molare Extinktion $\varepsilon\left(\mathrm{cm}^{2} / \mathrm{Mol}\right)$ als Funktion von $\lambda$ aufgetragen) zeigt Abbildung 1 (nach 10).

Die Differenz der Absorptionswerte erreicht bei 480 und $570 \mathrm{~nm}$ ihr Maximum. Der Wellenlängenbereich um 480 und $570 \mathrm{~nm}$ ist deshalb für die photometrische Endpunktbestimmung besonders geeignet.

Für eine scharfe Endpunktsbestimmung sind nach Forturs und Mitarbeitern (11) noch folgende Bedingungen entscheidend: 
Die Komplexbildungskonstante der Titersubstanz mit Calcium soll schr vicl größer als die der Indikatorsubstanz sein. Als Faustregel gilt, daß die Differenz, der Logarithmen beider Größen mindestens 4 sein soll. Bei pH-Werten $>12,5$ ist die Differenz zwischen beiden Größen ausreichend. Ferner soll die Komplexbildungskonstante des Indikators und die Metallionenkonzentration möglichst groß, dic Indikatorkonzentration dagegen möglichst klein sein.
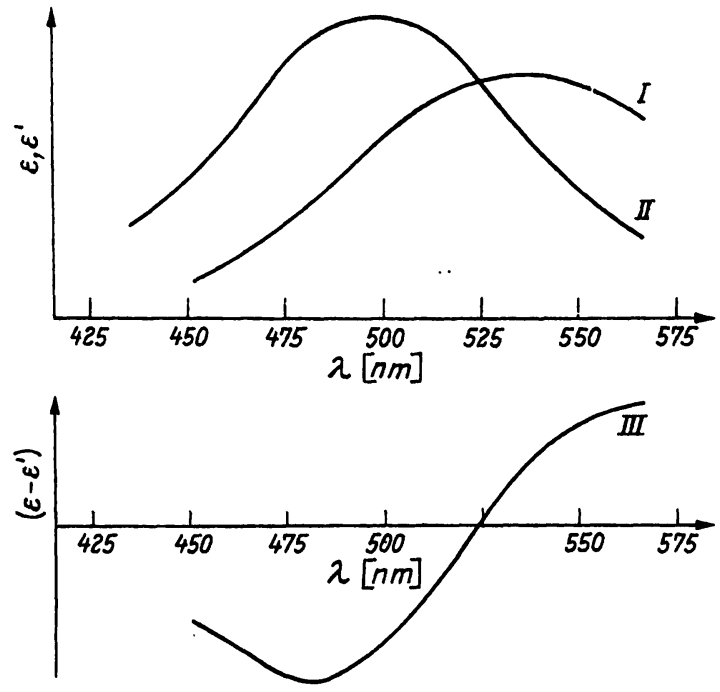

Abb. 1

Absorptionsspcktrum von Murexid (I) und seinem Calciumchelat (II) sowic deren Differenzspektrum (III)

\section{Reagenzlösungen}

Zum Ansetzen der Reagenzlösungen verwendeten wir dest. Wasser, das aus einer Quarzapparatur nochmals redestillicrt wurde. Wir konnten damit den Leerwert schr klein haltên.

\section{Calciumustandard}

$49,9 \mathrm{mg}$ Calciumcarbonat p. a. der Fa. Merck wurden in $10 \mathrm{ml}$ $\mathrm{HCl}$ gelöst und dic Lösung auf $200 \mathrm{ml}$ aufgefüllt. Die Substanz wurde vorher bei $100^{\circ}$ getrocknet, um Spuren von Feuchtigkeit zu entfernen. Die Lösung enthält $10 \mathrm{mg}$ Calciumionen pro $100 \mathrm{~m} /$ Lösung. Durch entsprechende Verdüinnung werden daraus die Eichlösungen mit 2 bis $8 \mathrm{mg}$ Calciumionen pro $100 \mathrm{~m} /$ hergestellt.

\section{Murexid}

$15 \mathrm{mg}$ Murexid der Fa. Merck wurden in $25 \mathrm{~m} /$ Wasser gelöst und zur Stabilisierung der Lösung $25 \mathrm{ml}$ 1,2-Propylenglykol zugesetzt. Dic Murexidlösung wurde jeden Tag frisch hergestellt. Veränderungen der Indikatorlösung innerhalb eines Tages wurden nicht festgestellt.

\section{EDTA}

Als Titerlösung verwendeten wir eine $2,5 \mathrm{~mm}$ Lösung des Dinatriumsalzes der Äthylendiamintetraessigsäure (Titriplex III). $1,861 \mathrm{~g}$ Titriplex III wurden in Wasser aufgelöst und die Lösung auf $2 /$ aufgefüllt.

\section{N Natriumby'droxj'd}

\section{Apparate}

Zur Endpunktsbestimmung der Titration benutzten wir das Photometer Eppendorf ohne Linearisierungsglied mit einem Aufsatz für photometrische Titrationen mit einem Magnetrührer der gleichen Firma. Wir arbeiteten mit dem Filter Cd $480 \mathrm{~nm}$. An das Photometcr war (wegen der hohen Ausgangsspannung) mittels eines Adapters Type PHA 801 ein Millivoltmeter (Titrator TTT 1) und ein Potentiometerschreiber (Titrigraph) der Fa. Radiometer angeschlossen (Abb. 2).

Titriert wurde mit der automatischen Bürette ABU 1 der gleichen Firma. Der Kolbeninhalt der Bürette betrug $250 \mu /$. Als Titrierund Vergleichsküvetten dienten quadratische Küvetten von $2 \mathrm{~cm}$ Schichtdicke und $4 \mathrm{~cm}$ Höhe, in denen magnetisch gerührt wurde.

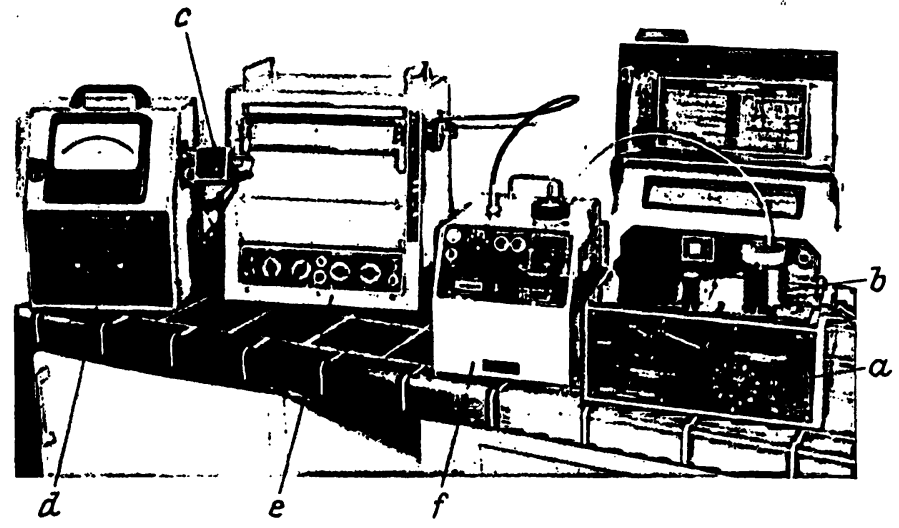

Abb. 2

Apparateanordnung: Photometer Eppendorf (a) mit Aufsatz für photometrische Titrationen (b) der gleichen Firma. Der Adapter (c) verbindet das Photometer mit dem Millivoltmeter (d) (Titrator TTT 1), das an den Potentiometerschreiber (e) (Titrigraph) angeschlossen ist. Uber die bicgsame Welle wird die Feder des Potentiometerschreibers von der Bürette $(f)$ aus angetrieben. Potentiometer und Mcßzclle sind gegen ein vorgegebencs Potential in Serie geschaltet, und die Bürette kompensiert dic durch den

Potentiometerschreiber vorgegebene Spannungsänderung

\section{Durchführung der Messung}

Als Vergleichslösung diente eine austitrierte L.ösung. In die Vergleichsküvettc wurden $8,5 \mathrm{~m} /$ dest. Wasser, $2 \mathrm{~m} / 2 \mathrm{~N}$ Natriumhydroxydlösung, $0,3 \mathrm{~m} /$ Murexidlösung, $100 \mu l$ Calciumstandardlösung und $200 \mu /$ EDTA-Lösung pipetticrt. Zum Pipettieren von Mikrolitervolumina verwendeten wir Eppendorfpipetten. Die Küvette mit der Vergleichslösung wurde mittcls cines $6 \mathrm{~mm}$ starken Gummiringes in den Titricraufsatz eingesetzt und nach kurzem magnetischem Rühren der Nullpunkt am Photometer eingestellt. In die Titrierküvette wurden anschlicßend $8,5 \mathrm{~m} /$ dest. Wasser, $2 \mathrm{~m} / 2 \mathrm{~N}$ Natriumhydroxydlösung, $0,3 \mathrm{~m} /$ Murexid und $100 \mu l$ der zu titricrenden Calciumlösung cinpipetticrt.

Die Vergleichsküvette wurde dann aus dem Titrieraufsat\% herausgehoben, die Titricrküvette eingesetzt und die Extinktion der Lösung durch Heraufschalten ciner Verstärkerstufe am Photometer in einen gut meßbaren Bercich gebracht. Die Extinktion der Lösung liegt dann etwa zwischen $E=0,3-0,4$. Anschließend wurde mit Hilfe des Adapters der Mcßbereich am Millivoltmeter eingestellt. Titriert wurde in Down-Scale mit ciner Schreibereichung von $-10 \mathrm{mV} / \mathrm{cm}$, eincr Kompensation von $100 \mathrm{mV}$ und einem Papiervorschub von $40 \mathrm{~mm} / \mathrm{Min}$. Dic Titriergeschwindigkcit wurde auf die Rührgeschwindigkeit abgestimmt. Wir titricrten mit einer mittleren Geschwindigkeit von etwa $0,1 \mathrm{~m} /$ Titricrflüssigkeit pro Min. (Speed 2 der Bürette). Zum Rühren verwendeten wir einen relativ kleinen Rührmagneten (etwa $1,5 \mathrm{~cm}$ lang) mit Teflonumhüllung. Die Rührung ist ausreichend, dic Oberfläche der Lösung aber bleibt ruhig. Mit dieser Anordnung crreichten wir eine sehr ruhige Photometeranzeige, die für cinc scharfe Endpunktbestimmung und einen geradlinigen Vcrlauf der geschriebenen Kurven entscheidend ist.

Ein stets reproduzierbarer Mehrverbrauch an EDTA-Lösung crwies sich als additive Größe und konnte als solche aus der Differenz zweier Titrationen von 10 und $15 \mu g \mathrm{Ca}^{++}$bestimmt und als Ieerwert abgezogen werden.

\section{Ergebnisse und Diskussion}

Bei der Titration werden Kurven erhalten, wie sie in Abbildung 3 als Beispiel zu seher sind.

Die Kurven zeigen einen völlig geradlinigen Verlauf und lassen sich durch Anlegen eines Lineals gut auswerten. Der Schnittpunkt beider Geraden ist der Endpunkt der Titration, von dem noch der Leerwert ab- 


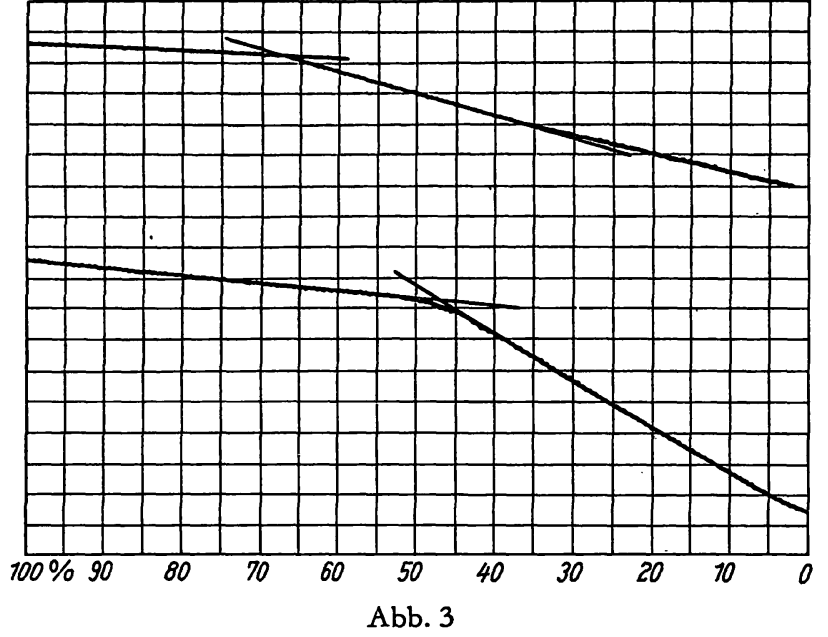

Titrationskurve: Photometrische Titration von $15 \mu \mathrm{g}$ (oben) bzw. $10 \mu \mathrm{g}$ (unten) $\mathrm{Ca}^{++}$mit $2,5 \mathrm{~mm}$ EDTA-Lösung und Murexid als Indikator

gezogen werden muß. Das Papier des Schreibers ist in Prozent geeicht. $250 \mu l$, der Inhalt der Bürette, entsprechen 100\%. $100 \mu l$ 2,5 mm EDTA-Lösung (40\% auf dem Papier) sind $10 \mu \mathrm{g} \mathrm{Ca}++$ äquivalent. Die Eichlösungen enthielten $2-10 \mathrm{mg}$ Calciumionen pro $100 \mathrm{ml}$, das entspricht 2-10 $\mu \mathrm{g}$ in $100 \mu \mathrm{l}$. Um den Fehler der Methode zu ermitteln, wurden für jede Eichlösung mehrere Bestimmungen durchgeführt.
Die Meßergebnisse sind in Tabelle 1 und 2 zusammengestellt. Der maximale Fehler der Einzelbestimmung liegt bei $0,13 \mu \mathrm{g}$.

Der mittlere Fehler beträgt im klinisch interessanten Bereich von $6-15 \mathrm{mg} / 100 \mathrm{~m} l$ etwa $1,5 \%$.

Tab. 1

Typische Verteilung der gefundenen Werte um einen vorgegebenen

\begin{tabular}{ccc}
\hline vorgegeben $(\mu \mathrm{g})$ & gefunden $(\mu \mathrm{g})$ & $\begin{array}{c}\text { max. Fehler der } \\
\text { Bestimmung }(\mu \mathrm{g})\end{array}$ \\
\hline 10 & 10,125 & 0,13 \\
& 10,125 & \\
9,950 & \\
& 10,000 & \\
& $9,, 075$ & \\
& 10,000 & \\
& 10,000 & \\
& 10,050 & \\
& 10,000 & \\
\hline
\end{tabular}

Tab. 2

Ưbersicht über den mittleren Fehler der Einzelbestimmung im Bereich von $2-15 \mu \mathrm{g}$

\begin{tabular}{cccc}
\hline $\begin{array}{c}\text { vorgegeben } \\
(\mu \mathrm{g})\end{array}$ & $\begin{array}{c}\text { gefunden } \\
\text { Mittelwert }(\mu \mathrm{g})\end{array}$ & $\mathrm{n}$ & $\begin{array}{c}\text { mittlerer Fehler } \\
\text { der Einzel- } \\
\text { bestimmung }(\%)\end{array}$ \\
\hline 2 & $1,91 \pm 0,09$ & .10 & 4,5 \\
3 & $2,99 \pm 0,1$ & 10 & 3,33 \\
4 & $3,95 \pm 0,1$ & 10 & 2,5 \\
6 & $6,03 \pm 0,07$ & 10 & 1,17 \\
8 & $8,03 \pm 0,07$ & 10 & 0,875 \\
9 & $9,05 \pm 0,04$ & 10 & 0,67 \\
10 & $10,01 \pm 0,07$ & 10 & 0,7 \\
12 & $12,07 \pm 0,07$ & 10 & 0,58 \\
15 & $15,01 \pm 0,08$ & 10 & 0,53 \\
\hline
\end{tabular}

\title{
Literatur
}

1. Kramer, B. und F. F. TisdalL, J. biol. Chemistry 47, 475 (1921). - 2. Schwarzenbach, G., W. BiedermanN und F. Bangerter, Helv. chim. Acta 29, 811 (1946). - 3. Elirotr, W. E., J. biol. Chemistry 197, 641 (1952). - 4: FALES, F. W., J. biol. Chemistry 204, 577 (1953). - 5. Kibrick, A. C., M. Ross und H. E. Rogers, Proc. Soc. exp. Biol. Med. 81, 353 (1952). - 6. Siegmund, P. und H. J. Durce, Hoppe-Seylers Z. physiol. Chem. 320, 149 (1960). -
7. Copp, D. H., J. Laborat. Clin. Med. (S. Louis) 61, 1029 (1963). 8. Wiltiams, M. B. und J. H. Moser, Analytic. Chem. 25, 1414 (1953). - 9. Chalmers, R. A., Analyst 79, 519 (1954). - 10. Karsten, P., H. L. Kies und H. TH. J. van Engelen, Analytica chim. Acta (Amsterdam) 12, 64 (1955). - 11. Foriurn, J. M. H., P. Karsten und H. L. Kies, Analytica chim. Acta (Amsterdam) 10, 356 (1954).

\section{Flammenphotometrische Lithiumbestimmung im Serum}

\author{
Routinemetbode qur Übervacbung der Litbiumtherapie in der Psycbiatrie \\ Von P. Doerr und D. StAMM \\ Aus dem Max-Planck-Institut für Psycbiatrie, München
}

(Eingegangen am 21. Februar 1968)

Die Lithiumtherapie in der Psychiatrie bedarf der ständigen Kontrolle des Serumspiegels. Dafür wird eine einfache Routinemethode mit dem Eppendorf-Flammenphotometer beschrieben. Die Richtigkeit im Konzentrationsbereich 0,3-4,5 mVal/l ist geprüft, die Präzision beträgt als Variationskoeffizient bis zu 1,6\%. Die Störeinflüsse von Natrium, Kalium und Calcium sind geprüft; an der oberen therapeutischen Grenze von $1,8 \mathrm{mVal} / \mathrm{l}$ Lithium betragen sie weniger als $1 \%$.

During lithium therapy in psychiatry, the concentration of lithium in the serum must be continually monitored. A suitable routine method with the Eppendorf flame photometer is described.

The maximum error was $1.6 \%$ in the concentration range $0.3-4.5 \mathrm{~m}$. eq. $/ l$. of lithium. Interference by sodium, potassium and calcium was less than $1 \%$ with $1.8 \mathrm{~m}$. eq. $/ \mathrm{l}$. lithium, which is the upper therapeutic limit for lithium.

Die Behandlung verschiedener psychiatrischer Erkrankungen (1) mit Lithiumsalzen gewinnt zunehmend an Interesse. Wegen der geringen therapeutischen Breite (2) ist eine sorgfältige Überwachung der $\mathrm{Pa}$ tienten nötig. Neben der Beobachtung klinischer
Symptome ist vor allem die Kenntnis des Serumlithiumspiegels wichtig.

LANG und HERRMANN (3) haben eine flammenspektrophotometrische Methode für die Bestimmung der physiologischen Lithiumkonzentration im Serum ${ }^{-}(0,4$ 